\title{
PERANCANGAN APLIKASI MANAJEMEN PERALATAN JARINGAN KOMPUTER
}

\author{
Sudirman, Sumarsono, Anton Setiawan \\ Jurusan Teknik Informatika \\ Sekolah Tinggi Teknologi Adisutjipto \\ Yogyakarta \\ informatika@stta.ac.id
}

\begin{abstract}
Nowadays computer not only as a device, but also it needs to data access in order to more efficient and to do tasks that involve the other computers, so network administrator needs some ease and efficiency when configure and network troubleshoot. Therefore, with router a protocol can be share to the other network devices, beside that switch can also filters and flows the packet that exist in a LAN (Local Area Network), so it can work for anything protocol packet. This network equipment management application is to configure utility with input several data that available so that more efficient for user. The result of this application is can help administrator and newborn administrator to ease in configure router.
\end{abstract}

Keywords: Computer Network, Computer Network Equipment Management

\section{Pendahuluan}

Komputer saat ini bukan hanya perangkat yang berdiri secara tunggal, tetapi untuk keperluan akses data yang lebih efisien dan tugas-tugas yang melibatkan komputer lain, komputer harus bekerja pada sistem jaringan yang kompak dan saling terhubung.

Adapun perancangan network pada masa kini sangat berbeda jauh dengan perancangan network dimasa lalu, perancangan network dimasa lalu berdasarkan pada collapsed backbone yaitu arsitektur network dimana semua alat menuju ke sebuah backbone yang sama perancangan network masa kini dirincikan dengan sebuah arsitektur yang lebih datar berkat adanya router dana switch.

Administrator jaringan membutuhkan kemudahan serta efisiensi waktu pada saat konfigurasi dan troubleshoot jaringan. Hal ini sangat memberikan keuntungan baik pada topologi jaringan maupun pekerjaan tersebut. Misalnya pada topologi jaringan besar dibutuhkan tugas dan pekerjaan troubleshoot yang complex dan harus mengatur perangkatperangkat jaringan secara manual, seperti konfigurasi router dilakukan harus pada router akan dikonfigurasi sehingga akan merepotkan administrator untuk mengatur tiap perangkat tersebut satu-persatu. 


\section{LANDASAN TEORI}

\section{Peralatan Jaringan}

\section{Console Port}

Console port adalah sebuah port pada router yang disediakan untuk menghubungkan router tersebut pada "dunia luar". Sebuah kabel roll over dibutuhkan untuk menghubungkan serial interface pada PC dan console port pada router tersebut. Setelah router terhubung dengan PC, router dapat dikonfigurasi dengan menjalankan aplikasi HyperTerminal dari PC.

\section{Router}

Router adalah perangkat antara yang dapat digunakan untuk menghubungkan dua jaringan lokal yang mempunyai protokol yang sama pada lapisan jaringan OSI sedangkan protokol padalapisan fisik dan data link berbeda. Router merupakan perangkat pencari jalan yang handal pada situasi interkoneksi yang kompleks, karena memiliki kemampuan manajemen jaringan yang baik sehingga router sangat tepat digunakan pada pembangunan jaringan komputer skala luas. Router dapat dilihat pada gambar 1 (Budi Sutedjo,2003 2004)

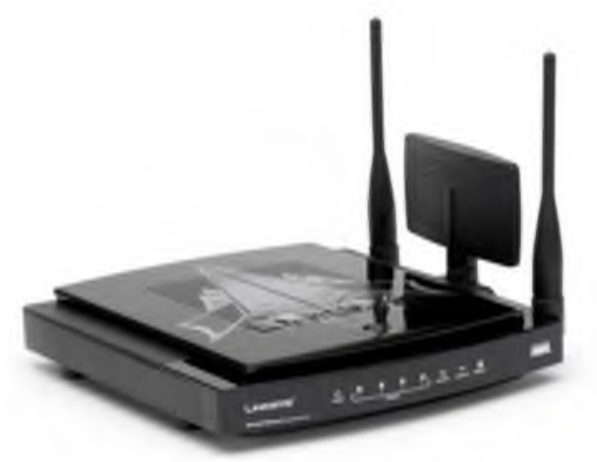

Gambar 1 Router

Fungsi Router:

1. Router berfungsi utama sebagai penghubung antar dua atau lebih jaringan untuk meneruskan data dari satu jaringan ke jaringan lainnya. Perbedaannya dengan Switch adalah kalau switch merupakan penghubung beberapa alat untuk membentuk suatu Local Area Network (LAN).

2. Router men-tranmisikan informasi dari satu jaringan ke jaringan lain yang sistem kerjanya mirip dengan bridge.

\section{Switch}

Switch adalah hub tetapi switch memiliki kemampuan untuk mentrasfer data hanya pada port yang dituju, berbeda dengan hub yang mem-broadcast data yang dating kesemua port yang dimiliki termaksud port tempat data tersebut berasal, perbedaan ini membuat switch lebih cepat dalam mentrasferkan data walaupun memiliki kecepatan yang sama. Switch dapat dilihat pada gambar 2 . 


\section{Gambar 2 Switch}

\section{Fungsi Switch :}

1. Store and Forward yang berfungsi meneruskan frame setelah data di terima secara lengkap.

2. Cut-Through yang berfungsi meneruskan frame tanpa menunggu penerimaan frame secara lengkap.

3. Fragment Free (Hybrid) merupakan kompromi dari kedua jenis switch diatas. Switch juga diperkuat oleh teknologi Virtual Local Area Network (VLAN) dimana mampu Mensegmentasi jaringan LAN. Switch juga dapat berfungsi sebagai Spanning Tree protokol yang bersifat menilai suatu jalur itu sibuk maka dia switch akan memilih jalur lain yang tidak sibuk.

\section{Item Konfigurasi}

1. Port adalah aplikasi atau proses spesifik yang mengijinkan untuk terjadinya komunikasi data antar sistem operasi komputer.

2. Baud rate adalah kecepatan transfer data per-second panjang.

3. Data bits adalah variabel atau kuantitas dalam menghitung komputer yang diwakili oleh bit 0 dan 1.

4. Stop bits dikirim pada akhir dari setiap karakter yang mengijinkan penerimaan sinyal hardware untuk mendeteksi berakhirnya karakter dan untuk mengsingkronisasikan dengan karakter yang ada.

5. Parity adalah langkah-langkah untuk mendeteksi error pada saat Pengiriman.

6. Flow Control adalah proses untuk mengatur kecepatan transmisi data diantara dua poin untuk mencegah terjadinya overflow pada saat pengiriman data dari pengirim yang memiliki kecepatan lebih cepat kepenerima yang lambat.

\section{Jaringan Komputer}

Jaringan komputer adalah himpunan "interkoneksi" antara 2 komputer autonomous atau lebih terhubung dengan media tranmisi kabel atau tanpa kabel (wireless). Bila sebuah komputer dapat membuat komputer lainnya restart, shutdown, atau memlalui kontrol lainnya, maka komputer-komputer tersebut autonomous (tidak melakukan kontrol terhadap komuter lain ). Berikut adalah beberapa jenis jaringan LAN (Local Area Network), MAN (Metropolitan Area Network), WAN (Wide Area Network), VLAN (Virtual Local Area Network (Melwin Syafrizal, 2005).

\section{TCP/IP(TransmissionControlProtocol/Internet Protocol)}

TCP/IP adalah konsep berbasis internet dan menjadi kerangka kerja pengembangan sebuah paket lengkap standar komunikasi komputer. Hampir semua vendor komputer saat ini menyediakan dukungan untuk arsitektur ini. Arsitektur lain yang dikenal luas adalah model rujukan Open System Interconnection (OSI). OSI adalah arsitektur terstandarisasi yang sering digunakan untuk menggambarkan fungsi-fungsi komunikasi namun saat ini jarang di implementasikan (Sutanta, 2005). 


\section{Implementasi Dan Analisa}

\section{Uji Coba Sistem}

Uji coba sistem dilakukan dengan menggunakan 1 buah router untuk menyampaikan paket dari satu jaringan ke jaringan lainnya dan 3 unit komputer. Dari beberapa unit komputer tersebut, satu unit komputer tertanam aplikasi remote perangkat jaringan komputer dan komputer yang lain bertindak sebagai penerima paket.

\section{Konfigurasi Jaringan}

Pada komputer 192.168.44.1 ingin mengirim data ke 192.168.88.1, menyadari bahwa alamat tujuan tidak berada pada jaringan local, sehingga komputer mencari daftar default gateway pada property TCP/IP yaitu 192.168.44.7. Paket data kemudian dikirim ke gateway tersebut. Pada IP 192.168.44.7 paket data tersebut kembali diperiksa, dan ditemukan pada tabel routing bahwa paket tersebut dapat dikirim ke jaringan 192.168.88 melewati IP 192.168.88.5. Pada IP 192.168.88.5 akhirnya data dapat ditransmisi ketujuan yaitu 192.168.88.1.

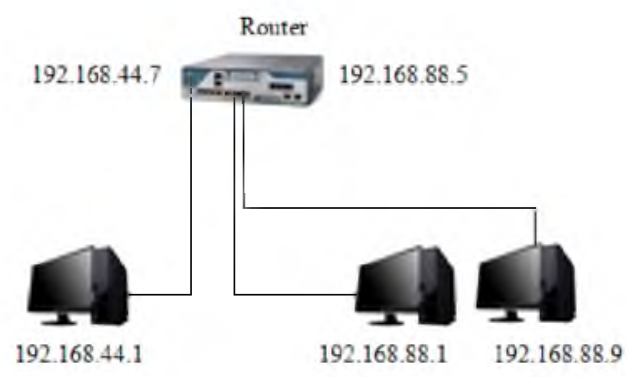

Gambar 3 Konfigurasi Jaringan

\section{Uji Coba Aplikasi Remote Perangkat Jarigan}

\section{Konfigurasi Untuk Router}

Sebelum pengguna melakukan konfigurasi pada menu configure pengguna melihat settingan melalui diakses Start $>$ My komputer $>$ Klik kanan $>$ Manage $>$ Device Manager $>$ Port $C O M>$ Kemudian klik kanan pada port serial yang terhubung pada perangkat cisco. Kemudian pada menu properties terdapat tampilan setting kemudian pilih menu port setting. Cara settingan port seperti pada gambar 4 . Untuk melakukan remote pada perangkat tampilan utama seperti pada gambar 5. Dan konfigurasi perangkat router siap digunakan seperti pada gambar 6. Jika aplikasi connect maka langsung membuat nama pada router seperti pada gambar 7 . Dan untuk memberi alamat pada router seperti pada gambar 8. Dan memberi alamat pada network seperti pada gambar 9 . 


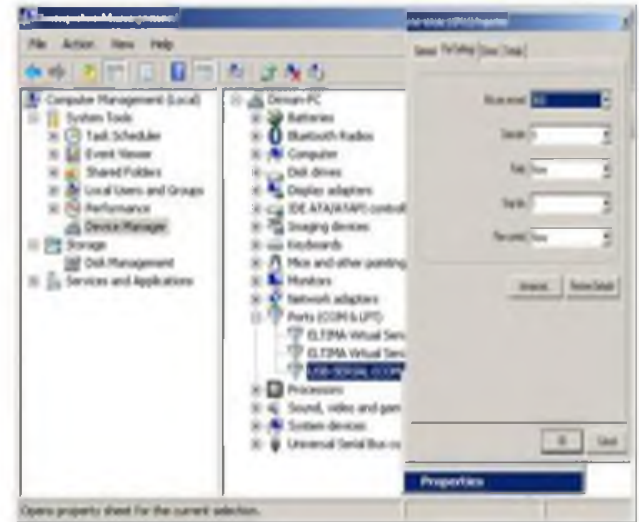

Gambar 4 cara koneksikan port ke perangkat

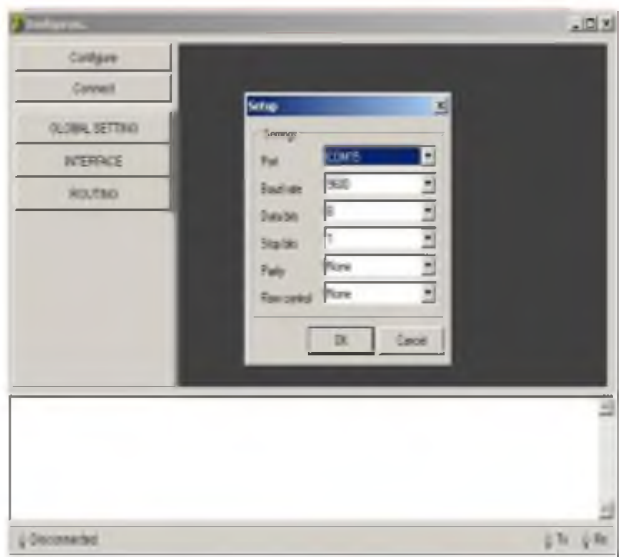

Gambar 5 Configure pada Router

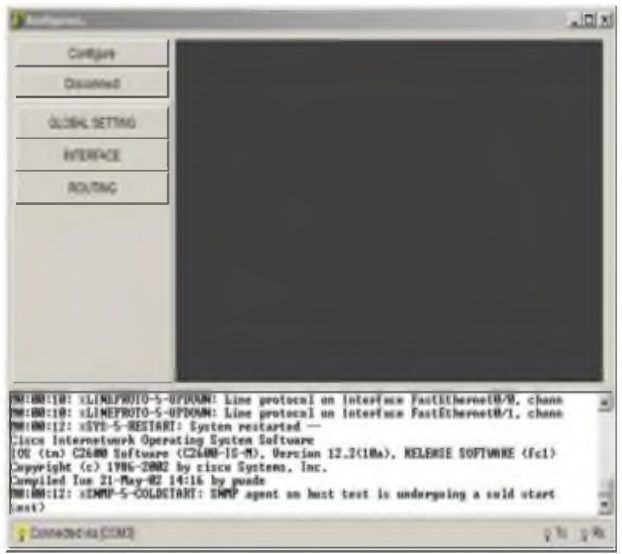

Gambar 6 aplikasi connect dengan perangkat 


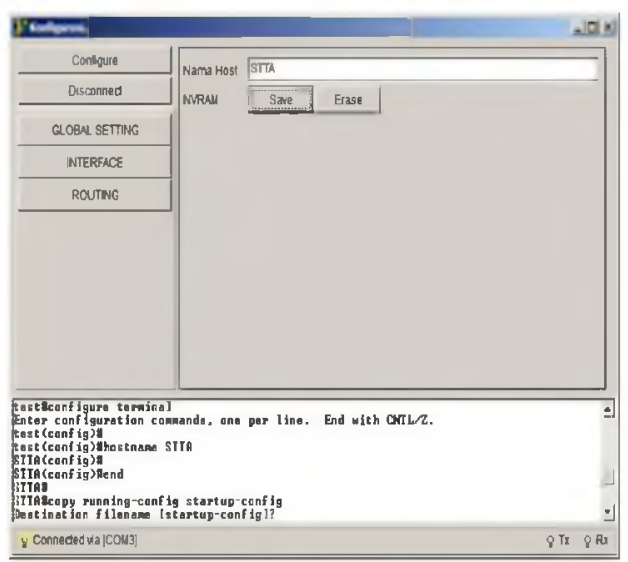

Gambar 7 Global Setting

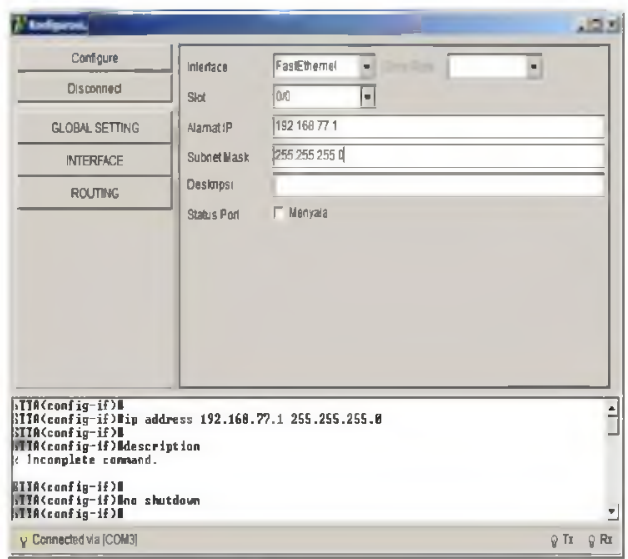

Gambar 8 FastEthernet

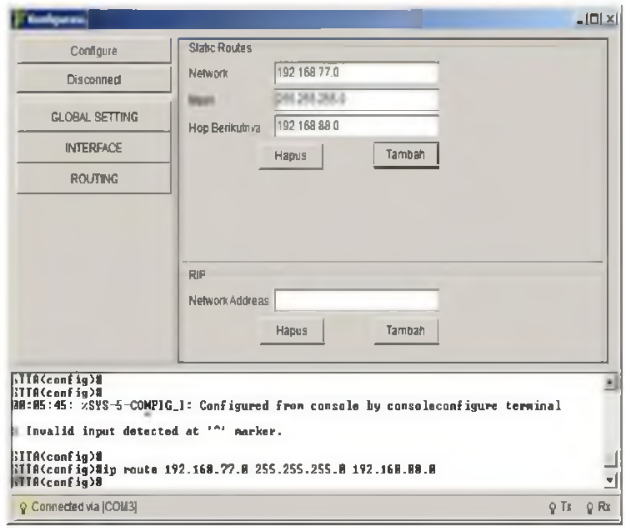

Gambar 9 Memberi alamat network

\section{Konfigurasi Untuk Switch}

Tidak berbeda jauh dengan router ketika user/pengguna memilih untuk konfigurasi switch maka pada tampilan switch seperti pada gambar 11, setelah aplikasi connect pada perangkat maka memberi nama pada switch pada gambar 12, dan setelah memberi nama pada switch maka pengguna mengisi VLAN seperti pada gambar 13, Setelah semua telah dikonfigurasi dan untuk melihat hasil konfigurasinya seperti pada gambar 14 . 


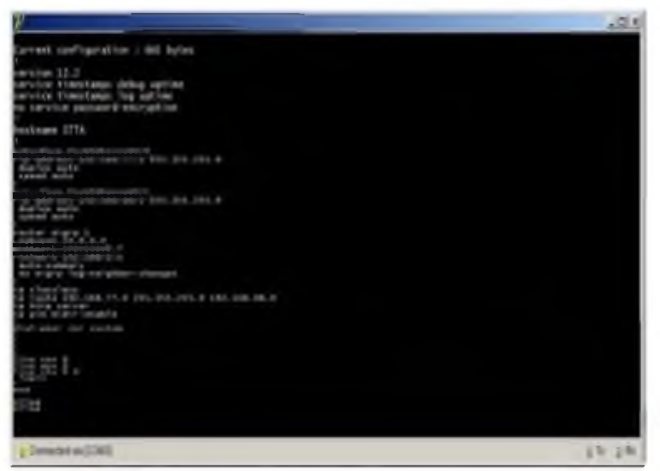

Gambar 14 hasil dari konfigurasi

\section{Analisa Sistem}

Hasil dari semua percobaan dapat dianalisa dari semua analisa adalah tentang proses mekanisme karja dari sistem secara keseluruhan. Secara keseluruhan hasil analisa terdiri dari konsep yang dibangun untuk menjadi sebuah sistem dengan apa yang telah dibahas pada bab sebelumnya.

Analisa dari hasil percobaan adalah :

1. Antara aplikasi ini dan perangkat jaringan dapat saling berkomunukasi dengan menggunakan port yang telah tersedia pada menu setup kemudian dihubungkan pada perangkat jaringan (Router).

2. Setelah aplikasi terhubung dengan perangkat jaringan (Router) maka aplikasi siap untuk dikonfigurasi sehingga akan terjadi pertukaran data yang dinginkan.

\section{Uji Coba Di Beberapa Tipe Router}

Setelah diuji coba pada router dapat diketahui kemampuan aplikasi ini dalam mengkonfigurasi berbagai tipe router. Hal ini ditunjukan pada table 1.

Tabel 1 Pengujian pada beberapa router

\begin{tabular}{|c|c|c|}
\hline No. & Tipe Router & Keterangan \\
\hline 1. & Cisco 2600 & Bisa \\
\hline 2. & Cisco 800 & Bisa \\
\hline
\end{tabular}

\section{Kesimpulan}

Dari hasil uji coba yang dilakukan dapat ditarik kesimpulan bahwa aplikasi ini dapat membantu administrator dalam melakukan remote pada jaringan komputer melalui port console, sehingga administrator dapat menghemat waktu dalam melakukan konfigurasi perangkatperangkat router, serta dapat digunakan sebagai pembelajaran untuk pemula yang ingin belajar mengenai router dan switch. 


\section{Saran}

Adapun saran yang diberikan untuk pengembangan tugas akhir ini adalah pengembangan aplikasi selanjutnya diharapkan dapat dioperasikan pada sistem operasi linux.

\section{Daftar Pustaka}

Seri Buku Pintar, 2005. Menjadi Administrator Jaringan Komputer, Edisi I, CV Andi Offset Andi Yogyakarta.

Sutedjo Budi, 2004. Konsep \& Perancangan Jaringan Komputer, Bangunan Satu Lantai, Gedung Bertingkat \& Kawasan, Edisi II, CV. Andi Offset Andi Yogyakarta.

Sutanta, 2005, Komunikasi Data dan Jaringan Komputer, Graha Ilmu, Yogyakarta.

Syafrizal, 2005, Pengantar Jaringan Komputer, CV. Andi Offset Andi, Yogyakarta.

Madcoms, 2003, Pemrograman Borland Delphi 7, CV. Andi Offset Andi, Yogyakarta.

http://www.Duniakomputer.pengertiankomputer.hyperterminal<<duniakomputer.html diakses pada 28 Januari 2012

http://wwww.ojs.library.stikom.edu. Diakses pada 28 Januari 2012

http://woww.repository.usu.ac.id. Diakses pada 03 Februari 2012

http://www.papers.gunadarma.ac.id. Diakses pada 04 Februari 2012

http://www.ebookbrowse.com/c-1-analisis-perancangan-dan-implementasi-firewall-dan-traffic-filteringmenggunakan-cisco-router-pdf-d182128892.diakses pada 05 Februari 2012. 